\title{
INTENSITAS PENCAHAYAAN ALAMI PADA RUANG PERTEMUAN DI GEDUNG COT, FAKULTAS TEKNIK GOWA, UNIVERSITAS HASANUDDIN
}

\author{
Annajma Nurul Wika ${ }^{1}$, Nurul Jamala ${ }^{2}$ \\ Departemen Arsitektur, Fakultas Teknik, Universitas Hasanuddin \\ Jl. Poros Malino Km.6, Bontomarannu, Kabupaten Gowa, Sulawesi Selatan \\ Email : annajmanurulwika@gmail.com
}

\begin{abstract}
Abstrak
Pencahayaan merupakan faktor penting dalam melakukan aktivitas. Namun, pencahayaan yang berlebih juga dapat menimbulkan ketidaknyamanan dalam beraktivitas. Penelitian ini bertujuan untuk meneliti intensitas pencahayaan alami di ruang pertemuan gedung COT Fakultas Teknik Universitas Hasanuddin. Jenis penelitian yang dipakai oleh peneliti adalah penelitian kuantitatif dan menggunakan metode pengambilan data secara langsung menggunakan alat ukur lux meter yang kemudian disajikan dalam bentuk tabel. Kesimpulan dari penelitian ini yaitu intensitas cahaya alami di ruang pertemuan gedung COT lantai 1, lantai 2 dan lantai 3 semuanya melebihi standar 300 lux. Rata-rata besar intensitas cahaya pada luar bangunan dengan kondisi langit cerah pada pagi hari sebesar 29950 lux, siang hari sebesar 18360 lux dan sore hari sebesar 14550 lux. Rata-rata intensitas cahaya pada luar bangunan dengan kondisi langit berawan pada pagi hari sebesar 9200 lux, siang hari sebesar 8750 lux dan sore hari sebesar 9350 lux. Rata-rata besar intensitas cahaya pada luar bangunan dengan kondisi langit mendung pada pagi hari sebesar 3250 lux, siang hari sebesar 6610 lux dan sore hari sebesar 5425 lux. Besarnya intensitas cahaya alami di luar bangunan dengan kondisi langit apapun sangat berpengaruh terhadap pencahayaan alami yang masuk ke bangunan. Semakin besar intensitas cahaya luar bangunan, maka semakin besar pula pencahayaan yang masuk ke bangunan.
\end{abstract}

Kata kunci : intensitas cahaya, pencahayaan alami, ruang pertemuan, gedung COT.

\begin{abstract}
Title:Natural Light Intensity Analysis in the Meeting Room at COT Building, Gowa Engineering Faculty, Hasanuddin University

Lighting is an essential factor in supporting out activities. However, excessive brightness can also cause discomfort. This study aims to examine the intensity of natural lighting in the meeting room of the COT building, Faculty of Engineering, Hasanuddin University. This type of research used is quantitative analysis and data collection methods directly using the lux meter measuring instrument, then presented in tabular form. The study's conclusion is that the intensity of natural lighting in the meeting room of the 1st floor, 2nd and 3rd-floor COT buildings, all exceeding 300 lux from the lighting standards. The average significant light intensity outside the building with clear sky conditions in the morning is 29950 lux; daytime is 18360 lux and afternoon is 14550 lux. The average light intensity outside the building with cloudy sky conditions in the morning is 9200 lux, daytime is 8750 lux, and afternoon is 9350 lux. The average significant light intensity outside the building with cloudy sky conditions in the morning is 3250 lux, daytime is 6610 lux, and the afternoon is 5425 lux. The magnitude of the natural light intensity outside the building with any sky conditions significantly affects the natural lighting in the building. The higher the intensity of the sun light outside the building, the higher the illumination that comes to the building.
\end{abstract}

Keywords: light intensity, natural light, meeting room, COT building. 


\section{Pendahuluan}

Indonesia yang beriklim tropis lembab memiliki intensitas radiasi matahari yang kuat, temperatur udara yang relatif tinggi, kelembaban udara yang tinggi, serta keadaan langit yang selalu berawan, dimana faktor-faktor ini selalu terjadi hampir sepanjang tahun (Lippsmeier, 1988). Cahaya matahari sebagai sumber pencahayaan alami merupakan salah satu sumber energi terbarukan yang sangat berlimpah di Indonesia. Sebagai negara yang melintang dari barat sampai ke timur dan dilalui garis khatulistiwa, negara ini sangat kaya akan energi yang dihasilkan oleh matahari. Kondisi geografis ini pula yang membawa pada stabilnya cahaya matahari yang diterima di seluruh wilayah di Indonesia sepanjang tahun.

Salah satu peran yang yang diberikan cahaya alami pada bangunan adalah dalam hal penerangan (Manurung, 2012). Pencahayaan merupakan salah satu faktor penting dalam perancangan ruang. Ruang yang telah dirancang tidak dapat memenuhi fungsinya dengan baik apabila tidak disediakan akses pencahayaan. Pencahayaan di dalam ruang memungkinkan orang yang menempatinya dapat beraktivitas dengan baik, khususnya dalam sebuah bangunan yang berfungsi sebagai kantor. Pencahayaan yang baik akan membantu kita mengerjakan pekerjaan dan membuat kita merasa nyaman ketika mengerjakannya. Walaupun terkesan sederhana, pernyataan ini merupakan tujuan dari lighting design, yaitu untuk menciptakan kenyamanan, suasana yang menyenangkan dan ruang yang fungsional (Lam, 1977).
Menurut William M.C Lam (1977), pemanfaatan sinar matahari yang terbaik tidak hanya untuk efisiensi energi dan menjaga agar biaya listrik tidak meningkat, tetapi yang lebih utama adalah untuk membuat nyaman, lingkungan yang bercahaya menyenangkan bagi penghuninya. Untuk itu, dalam pemanfaatan sinar matahari harus diberikan prioritas tertinggi. Kualitas pencahayaan alami yang baik tidak terlepas dari distribusi cahaya yang masuk melalui jendela (bukaan) dan orientasi arah bukaan. Semakin luas bukaan, maka akan semakin besar cahaya yang masuk ke dalam ruang. Kualitas pencahayaan alami yang baik juga dipengaruhi oleh letak bukaan terhadap arah datangnya sinar matahari. Bangunan yang berada di wilayah beriklim tropis lembab mendapatkan intensitas penerangan cahaya matahari yang melimpah. Dengan lama penyinaran matahari relatif stabil sepanjang tahun yaitu antara pukul $06.00-18.00$ atau antara 10-12 jam (Koenigsberger, 1974:76).

Salah satu faktor yang mengganggu kenyamanan kerja seorang tenaga kerja adalah adanya penerangan di tempat kerja yang kurang dari standar maupun pencahayaan yang melebihi standar. Setiap hari manusia terlibat pada suatu kondisi lingkungan kerja yang berbeda-beda, dimana perbedaan kondisi tersebut sangat berpengaruh terhadap kemampuan manusia. Manusia akan mampu melaksanakan kegiatannya dengan baik dan mencapai hasil yang optimal apabila lingkungan kerjanya mendukung. Salah satunya adalah penerangan yang baik.

Gedung COT (Center of Technology) adalah salah satu bangunan yang berada di Fakultas Teknik Universitas Hasanuddin, Makassar, Sulawesi 
Selatan. Gedung COT terdiri dari 3 lantai yang digunakan sebagai kantor (administrasi), sehingga seluruh pengguna bangunan ini adalah dosen, pegawai dan karyawan yang bekerja di Fakultas Teknik Universitas Hasanuddin. Aktivitas yang dilakukan di gedung COT sebagian besar bekerja dengan komputer sehingga aktivitas di gedung COT tergolong dalam visual activities yang tinggi. Desain Bangunan pada gedung COT tersebut sangat unik. Sebagian dinding luar bangunan tersebut menggunakan kaca sebagai lapisan dinding luar bangunan. Seperti yang kita ketahui sifat kaca pada umumnya yaitu tembus pandang (transparan), sehingga cahaya sinar matahari langsung masuk ke bangunan.

Berdasarkan situasi di atas, maka peneliti tertarik untuk melakukan evaluasi mengenai pencahayaan alami yang ada di gedung COT, Fakultas Teknik Gowa, Universitas Hasanuddin. Peneliti tertarik untuk meneliti bagian gedung yang menggunakan kaca sebagai elemen dinding luar bagunan. Lantai 1 dan 2 digunakan sebagai ruang pertemuan, sedangkan lantai 3 digunakan sebagai ruang makan. Dalam penelitian ini, peneliti akan menganalisis intensitas cahaya pada ruang pertemuan dan ruang makan. Yang dimaksud dengan ruang pertemuan adalah suatu tempat, dimana setiap instansi mempunyai area berkumpul untuk mengeluarkan pendapat guna mengambil suatu keputusan demi kepentingan bersama. Sedangkan ruang makan merupakan ruang yang digunakan penghuni untuk aktivitas makan.

Kebutuhan pecahayaan berdasarkan SNI 03-6197-2000 untuk ruang pertemuan adalah 350 lux dan ruang makan 250 lux. Ada beberapa ruangan yang pencahayaan alaminya dianggap cukup, ada juga yang berlebihan. Oleh karena itu, hal ini dijadikan dasar dalam melaksanakan penelitian untuk mengetahui apakah ruang pertemuan tersebut sudah sesuai standar. Tujuan utama penelitian ini adalah untuk mengetahui kondisi pencahayaan alami pada ruang pertemuan gedung COT (Center of Technology) yang menggunakan kaca sebagai dinding luar bangunan. Seperti yang telah kita ketahui, kaca merupakan material tembus pandang sehingga cahaya matahari yang masuk ke bangunan menimbulkan silau. Hal ini menyebabkan pengguna ruang tidak nyaman saat melakukan aktivitas. Harapannya, hasil penelitian ini dapat menjadi referensi dalam mendesain bangunan.

\section{Metode Penelitian}

Penelitian dilakukan pada tanggal 1422 Juni 2017, dilaksanakan di beberapa ruang pertemuan pada gedung COT (Center of Tehnology) Fakultas Teknik, Universitas Hasanuddin.

Alat yang digunakan dalam penelitian ini adalah lux meter (lux meter/Krisbow type ALX-1300 serta software DIALUX EVO yang digunakan untuk simulasi. Sedangkan teknik pengumpulan data yang dilakukan pada penelitian ini memiliki beberapa langkah, sebagai berikut:

1. Pengukuran ruang penelitian (ruang pertemuan)

Pengukuran ruang pertemuan diukur langsung oleh tim peneliti, kemudian hasil pengukuran ruang pertemuan tersebut dicocokkan dengan gambar denah dalam file CAD ruang pertemuan.

2. Penentuan titik ukur dan pembagian zona 
Penentuan titik ukur ditentukan sesuai dengan SNI. Titik ukur pertama diambil $50 \mathrm{~cm}$ dari jendela, kemudian titik selanjutnya berjarak kurang dari 2 meter.

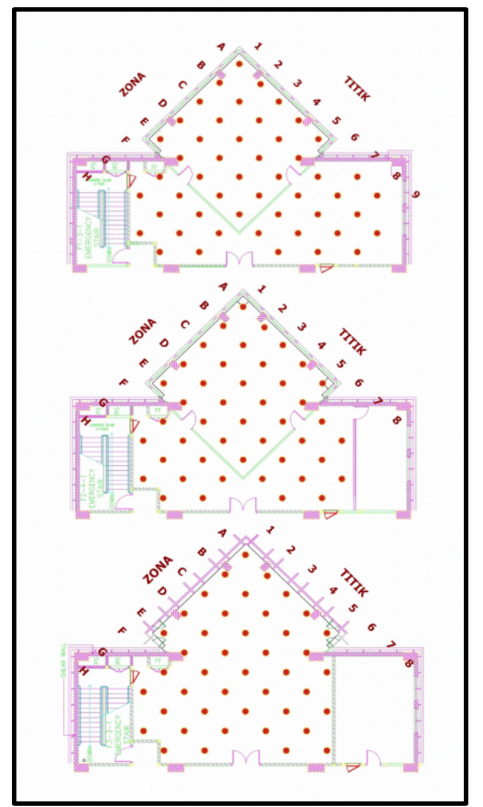

Gambar 1. Titik ukur pada ruang pertemuan lantai 1, lantai 2 dan lantai 3 Sumber: Analisis peneliti, 2017

Luas ruangan lantai 1, lantai 2 dan lantai 3 berbeda-beda. Namun, tiap titik diukur dengan jarak yang sama. Jumlah titik ukur lantai 1 sebanyak 49 titik, jumlah titik ukur lantai 2 sebanyak 47 titik dan jumlah titik ukur lantai 3 sebanyak 43 titik.

3. Pengukuran dengan lux meter (Krisbow type ALX-1300)

Lux meter digunakan untuk mengetahui data pencahayaan ruang di tiap-tiap titik dalam ruang penelitian (ruang pertemuan) dan pengukuran cahaya alami dari luar bangunan, yang kemudian didapat hasil pengukuran berupa angka. Kemudian angka tersebut dicatat dan analisis menggunakan software DIALUX EVO.

Analisis data dilakukan dengan cara membandingkan data yang diambil dari ruang penelitian yang telah diberikan variabel lainnya. Jadi, pada awalnya peneliti akan mengambil data berupa angka hasil pengukuran langsung di lapangan. Pengukuran dilakukan sesuai dengan titik yang telah diukur dan ditentukan. Pengukuran juga dilakukan di luar bangunan. Dalam sehari pengukuran dilakukan dalam 3 waktu berbeda, yaitu waktu pagi (pukul 08.00), waktu siang (pukul 12.00) dan waktu sore ( pukul 16.00).

4. Simuasi dengan software DIALUX EVO

\section{Software DIALUX EVO} digunakan untuk memperoleh data nilai lux/cahaya alami yang masuk ke bangunan pada sisi bangunan yang menggunakan kaca.

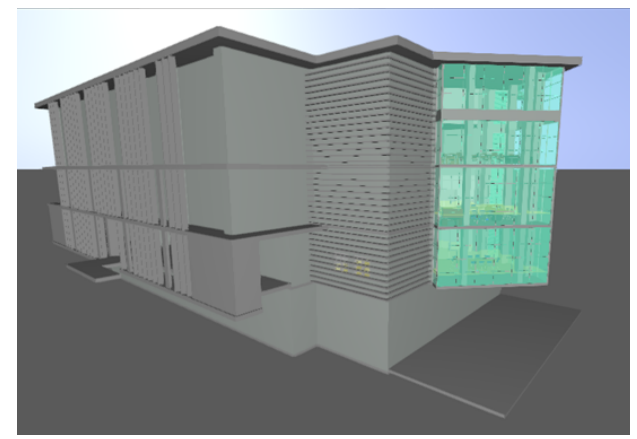

Gambar 2. Dialux gedung COT

Sumber: Analisis peneliti, 2017

Pada penelitian ini dilakukan observasi dan analisis terhadap pencahayaan alami yang masuk ke bangunan di gedung COT Fakultas Teknik Gowa. Jenis penelitian yang dipilih dan digunakan peneliti adalah penelitian kuantitatif. Penelitian dilakukan dengan menggunakan metode pengambilan data dan pengukuran secara langsung dengan alat ukur lux meter, kemudian didata dalam bentuk tabel dan hasil pengukuran dibandingkan dengan tabel pengukuran yang telah diberi perlakuan. Kemudian, peneliti memasukkan dan mengubah data 
pengukuran langsung ke dalam program simulasi untuk memperkuat data pengukuran secara langsung, sehingga peneliti dapat mengambil kesimpulan mengenai penelitian pencahayaan alami di ruang penelitian tersebut.

\section{Hasil dan Pembahasan}

Berdasarkan observasi awal peneliti, baik yang dilihat dan dirasakan langsung, kondisi awal ruang-ruang pertemuan yang ada di gedung COT (Center of Teknologi) ini sangat silau dan panas sehingga mengakibatkan ketidaknyamanan pengguna ruang dalam beraktivitas. Sehingga, pada ruangan tersebut dipasang Air Conditioner (AC). Peneliti mengambil 3 ruangan untuk penelitian ini. Peneliti tertarik meneliti di ruang tersebut karena elemen diding luar bangunan tersebut menggunakan kaca yang menyebabkan kesilauan.

1. Hasil Pengukuran Kondisi Langit Cerah

Hasil pengukuran kondisi langit cerah pagi, siang dan sore hari selama dua minggu pengukuran mulai tanggal 14 Juni 2017 - 22 Juni 2017 dapat dilihat pada grafik berikut ini.

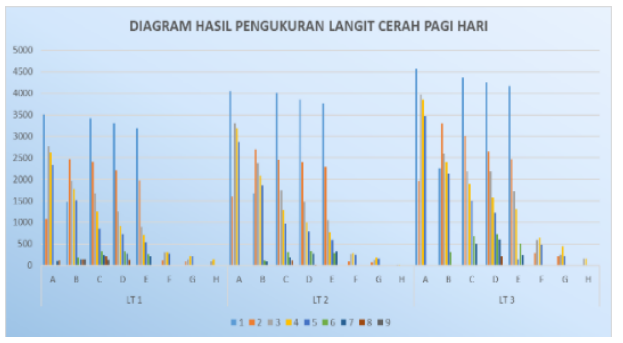

Gambar 3. Grafik hasil pengukuran kondisi langit cerah pagi hari pukul 08.00-09.00 WITA

Sumber: Analisis peneliti, 2017

Grafik di atas menunjukkan hasil pengukuran selama dua minggu pengukuran pada kondisi langit cerah pagi hari. Pada tanggal 16 Juni 2017 dengan kondisi langit cerah terjadi penurunan intensitas cahaya. Hal ini disebabkan karena intensitas cahaya kondisi luar sebesar 12200 lux.

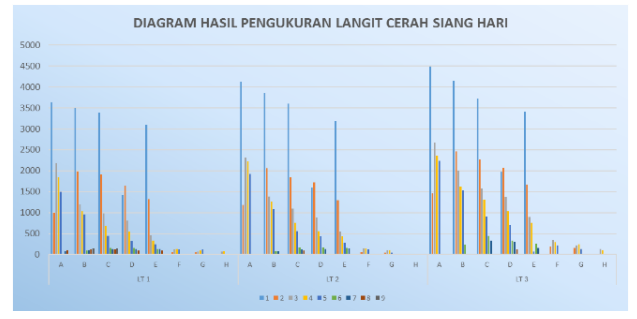

Gambar 4. Grafik hasil pengukuran kondisi langit cerah siang hari pukul 12.00-13.00 WITA

Sumber: Analisis peneliti, 2017

Grafik di atas menunjukkan hasil pengukuran selama dua minggu pengukuran pada kondisi langit cerah siang hari. Pada tanggal 16 Juni 2017 dengan kondisi langit cerah terjadi penurunan intensitas cahaya. Hal ini disebabkan karena intensitas cahaya kondisi luar sebesar 13100 lux. Intensitas cahaya tertinggi pada kondisi langit cerah sebesar 21600 lux dapat diihat pada tanggal 14 Juni 2017 dan 19 Juni 2017 sebesar 19800 lux.

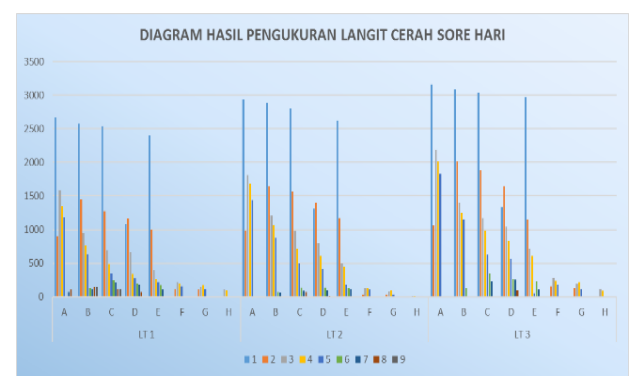

Gambar 5. Grafik hasil pengukuran kondisi langit cerah sore hari pukul 15.00-16.00 WITA

Sumber: Analisis peneliti, 2017

Grafik di atas menunjukkan hasil pengukuran selama dua minggu pengukuran pada kondisi langit cerah 
sore hari. Selama dua minggu pengukuran, langit cerah sore hari hanya terdapat pada tanggal 15 Juni dan 19 Juni 2017. Pada tanggal 15 Juni 2017 dengan kondisi langit cerah terjadi penurunan intensitas cahaya. Hal ini disebabkan karena intensitas cahaya kondisi luar sebesar 24400 lux.

2. Hasil Pengukuran Kondisi Langit Berawan

Hasil pengukuran kondisi langit berawan pagi, siang dan sore hari selama dua minggu pengukuran mulai tanggal 14 Juni 2017 - 22 Juni 2017 dapat dilihat pada grafik berikut ini.

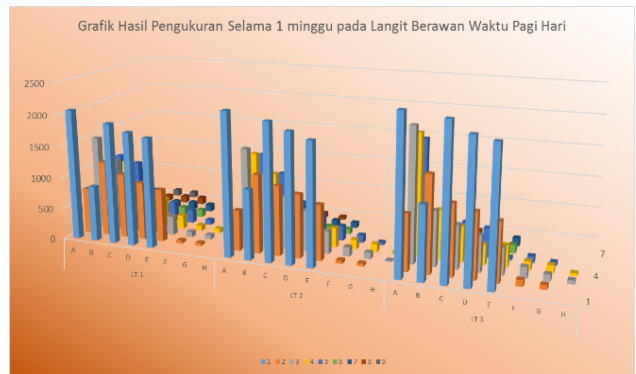

Gambar 6. Grafik hasil pengukuran kondisi langit berawan pagi hari pukul 08.00-09.00 WITA

Sumber: Analisis peneliti, 2017

Grafik di atas menunjukkan hasil pengukuran selama dua minggu pengukuran pada kondisi langit berawan pagi hari. Pada tanggal 20 Juni 2017 dengan kondisi langit berawan terjadi penurunan intensitas cahaya. Hal ini disebabkan karena intensitas cahaya kondisi luar sebesar 9200 lux.

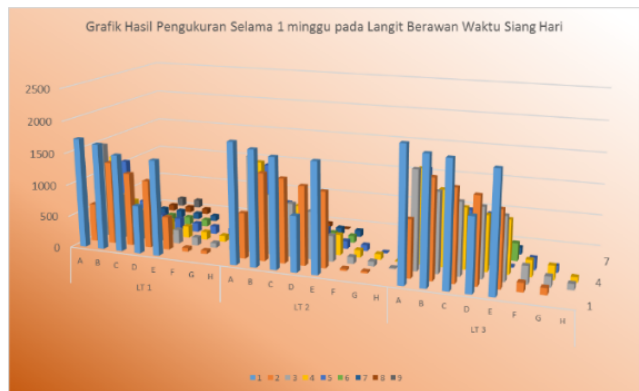

Gambar 7. Grafik hasil pengukuran kondisi langit berawan siang hari pukul 12.00-13.00 WITA

Sumber: Analisis peneliti, 2017

Grafik di atas menunjukkan hasil pengukuran selama dua minggu pengukuran pada kondisi langit berawan siang hari. Pada tanggal 21 Juni 2017 dengan kondisi langit berawan terjadi penurunan intensitas cahaya. Hal ini disebabkan karena intensitas cahaya kondisi luar sebesar 8750 lux. Intensitas cahaya tertinggi pada kondisi langit berawan sebesar 11100 lux.

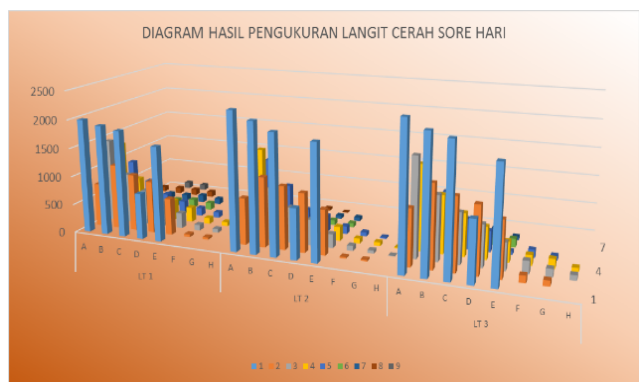

Gambar 8. Grafik hasil pengukuran kondisi langit berawan sore hari pukul 15.00-16.00 WITA

Sumber: Analisis peneliti, 2017

Grafik di atas menunjukkan hasil pengukuran selama dua minggu pengukuran pada kondisi langit berawan sore hari. Selama dua minggu pengukuran, langit berawan sore hari hanya terdapat pada tanggal 20 Juni 2017. Pada tanggal 20 Juni 2017 dengan kondisi langit berawan terjadi penurunan intensitas cahaya. Hal ini disebabkan karena intensitas 
cahaya kondisi luar sebesar 7750 lux.

3. Hasil Pengukuran Kondisi Langit Mendung

Hasil pengukuran kondisi langit mendung pagi, siang dan sore hari selama dua minggu pengukuran mulai tanggal 14 Juni 2017 - 22 Juni 2017 dapat dilihat pada grafik berikut ini.

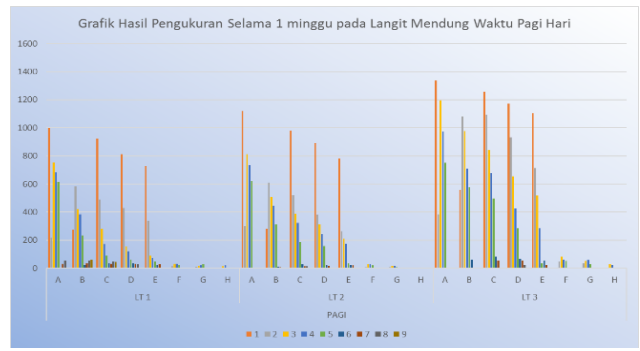

Gambar 9. Grafik hasil pengukuran kondisi langit mendung pagi hari pukul 08.00-09.00 WITA

Sumber: Analisis peneliti, 2017

Grafik di atas menunjukkan hasil pengukuran selama dua minggu pengukuran pada kondisi langit mendung pagi hari. Pada tanggal 20 Juni 2017 dengan kondisi langit mendung terjadi penurunan intensitas cahaya. Hal ini disebabkan karena intensitas cahaya kondisi luar sebesar 3250 lux.

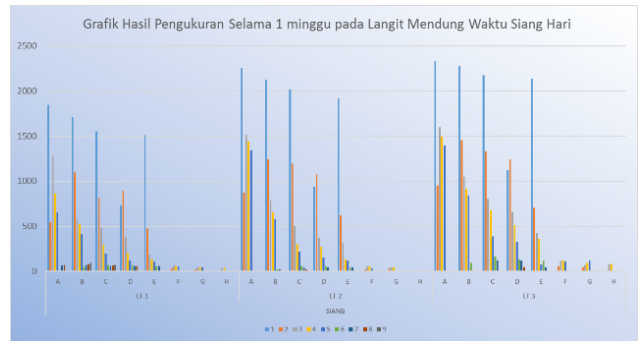

Gambar 10. Grafik hasil pengukuran kondisi langit mendung siang hari pukul 12.00-13.00 WITA

Sumber: Analisis peneliti, 2017

Grafik di atas menunjukkan hasil pengukuran selama dua minggu pengukuran pada kondisi langit mendung siang hari. Pada tanggal 20 Juni 2017 dengan kondisi langit mendung terjadi kenaikan intensitas cahaya. Pada waktu pagi tanggal 20 Juni 2017 intensitas cahaya kondisi luar bangunan sebesar 3250 lux kemudian naik pada siang hari sebesar 6610 lux. Intensitas cahaya tertinggi pada kondisi langit mendung sebesar 6610 lux dapat diihat pada tanggal 20 Juni 2017.

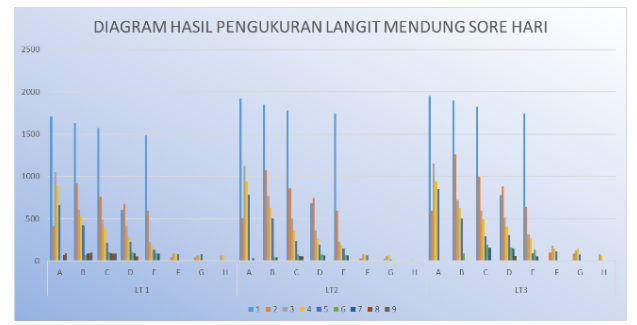

Gambar 11. Grafik hasil pengukuran kondisi langit mendung sore hari pukul 15.00-16.00 WITA

Sumber: Analisis peneliti, 2017

Grafik di atas menunjukkan hasil pengukuran selama dua minggu pengukuran pada kondisi langit mendung sore hari. Selama dua minggu pengukuran, langit mendung sore hari hanya terdapat pada tanggal 16 Juni 2017 dan 20 Juni 2017. Pada tanggal 16 Juni 2017 dengan kondisi langit mendung terjadi penurunan intensitas cahaya. Hal ini disebabkan karena intensitas cahaya kondisi luar sebesar 4450 lux.

4. Perbandingan Kondisi Cuaca Langit Cerah, Langit Berawan dan Langit Mendung Ruang Pertemuan

Perbandingan kondisi cuaca langit cerah, langit berawan dan langit mendung pada pagi, siang dan sore hari dapat dilihat pada grafik berikut ini. 


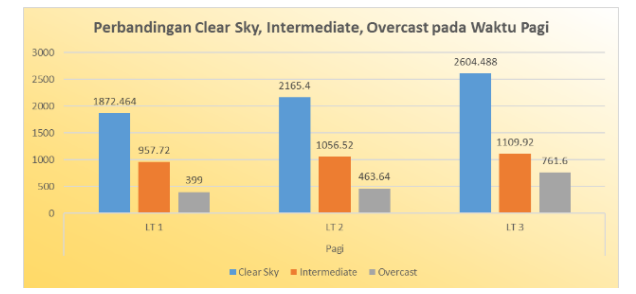

Gambar 12. Grafik perbandingan kondisi langit pagi hari pukul 08.00-09.00 WITA Sumber: Analisis peneliti, 2017

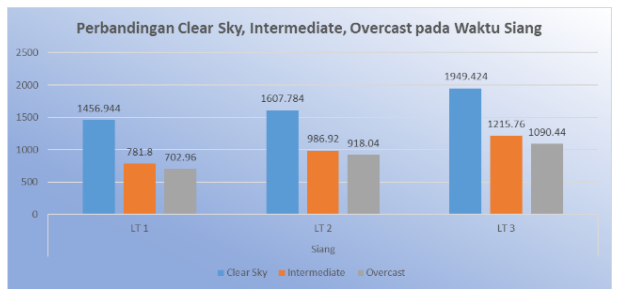

Gambar 13. Grafik perbandingan kondisi langit siang hari pukul 12.00-14.00 WITA Sumber: Analisis peneliti, 2017

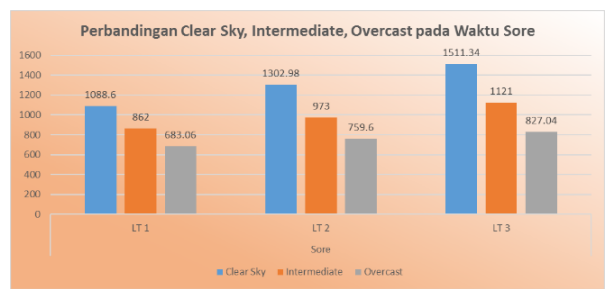

Gambar 14. Grafik perbandingan kondisi langit sore hari pukul 15.00-16.00 WITA Sumber: Analisis peneliti, 2017

Berdasarkan grafik di atas, kondisi langit cerah memiliki intensitas cahaya lebih tinggi dari kondisi langit berawan dan kondisi langit berawan memiliki intensitas cahaya lebih tinggi dari kondisi langit mendung. Jadi, dapat disimpulkan bahwa semakin cerah kondisi langit maka intensitas cahaya yang masuk ke dalam bangunan semakin tinggi, dan semakin gelap kondisi langit maka intensitas cahaya yang masuk ke bangunan semakin rendah.

\section{Hasil Simulasi DIALUX EVO}

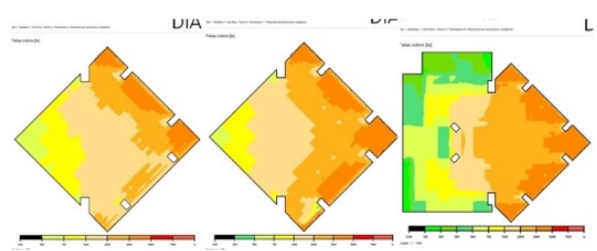

\section{Gambar 15. Hasil simulasi dengan reflektansi kaca jendela $\mathbf{2 5 \%}$ Sumber: Analisis peneliti, 2017}

Gambar di atas merupakan hasil simulasi ruang pertemuan dengan reflektansi kaca jendela sebesar $25 \%$. Hasil simulasi ini disesuaikan atau mendekati hasil pengukuran di lapangan. Sehingga, dengan memperbesar reflektansi kaca jendela sebesar 75\% maka hasilnya dapat disesuaikan dengan standar untuk ruang pertemuan sebesar 250-300 lux. Simulasi dilakukan pada kondisi cuaca langit berawan. Hal ini dilakukan agar intensitas cahaya pada saat langit cerah maupun langit mendung terpenuhi, meskipun terjadi selisih intensitas cahaya di titik ukur. Simulasi langit berawan dilakukan pada siang hari dimana pada kondisi cuaca ini merupakan kondisi cuaca langit tertinggi. Hal ini dilakukan untuk mengetahui intensitas cahaya alami yang masuk ke dalam ruang pertemuan di gedung COT Fakultas Teknik Gowa Universitas Hasanuddin.

\section{Kesimpulan}

Intensitas cahaya pada ruang pertemuan di gedung Center of Technology Fakultas Teknik Gowa Universitas Hasanuddin dengan kondisi langit cerah sangat melebihi standar 300 lux. Saat kondisi langit cerah rata-rata pencahayaan yang masuk ke bangunan pada lantai 1 sebesar 1872.5 lux, pada lantai 2 sebesar 2165.4 lux dan pada lantai 3 sebesar 2604.5 lux. Dapat kita 
simpulkan bahwa saat langit cerah intensitas cahaya yang masuk ke bangunan tidak sesuai dengan standar. Juga dapat kita lihat intensitas cahaya yang masuk ke lantai 1 lebih rendah dari pada lantai 2 lebih rendah dari pada lantai 3 (LT.1 $<$ LT.2 < LT.3). Sehingga dapat disimpulkan bahwa semakin tinggi lantai bangunan, semakin besar intensitas cahaya yang masuk ke bangunan.

Intensitas cahaya pada ruang pertemuan di gedung Center of Technology Fakultas Teknik Gowa Universitas Hasanuddin dengan kondisi langit cerah, berawan dan mendung pada waktu pagi hari setiap ruangan lantai 1 , lantai 2 dan lantai 3 di titik A2 dan B1 mengalami penurunan yang disebabkan cahaya matahari yang masuk dihalangi oleh kolom bangunan. Sedangkan kondisi langit cerah, berawan dan mendung pada waktu siang dan sore pada lantai 1, lantai 2 dan lantai 3 di titik A2 dan D1 mengalami penurunan yang disebabkan cahaya matahari yang masuk ke bangunan dihalangi oleh kolom bangunan.

Besarnya intensitas cahaya alami di luar bangunan dengan kondisi langit cerah, berawan dan mendung pada ruang pertemuan di gedung Center of Technology Fakultas Teknik Gowa Universitas Hasanuddin sangat berpengaruh terhadap cahaya alami yang masuk ke bangunan. Semakin besar intensitas cahaya luar bangunan, maka semakin besar cahaya yang masuk ke bangunan.

Dari hasil pengukuran selama 7 hari, rata-rata besar intensitas cahaya pada luar bangunan gedung Center of Technology Fakultas Teknik Gowa Universitas Hasanuddin dengan kondisi langit cerah pada pagi hari sebesar 29950 lux, pada siang hari sebesar 18360 lux dan pada sore hari sebesar 14550 lux, sedangkan ratarata besar intensitas cahaya pada luar bangunan dengan kondisi langit berawan pada pagi hari sebesar 9200 lux, pada siang hari sebesar 8750 lux dan pada sore hari sebesar 9350 lux. Rata-rata besar intensitas cahaya pada luar bangunan dengan kondisi langit mendung pada pagi hari sebesar 3250 lux, pada siang hari sebesar 6610 lux dan pada sore hari sebesar 5425 lux.

Berdasarkan kesimpulan tersebut, maka peneliti memberikan saran:

1. Hasil penelitian ini menyimpulkan bahwa kondisi langit cerah, berawan dan mendung pada pagi, siang dan sore hari sangat berpengaruh terhadap intensitas cahaya pada ruang pertemuan. Berdasarkan kesimpulan tersebut, peneliti melakukan simulasi dengan menggunakan aplikasi DIALUX EVO dengan menganalisis kondisi langit cerah pada siang hari. Dari hasil simulasi menunjukkan bahwa intensitas cahaya pada lantai 1 , lantai 2 dan lantai 3 memenuhi standar. Berdasarkan analisis ini, disarankan bahwa dalam mendesain bangunan sebaiknya memperhatikan koordinat pergerakan relatif matahari dalam setahun.

2. Hasil penelitian menyimpulkan bahwa reflektansi berpengaruh terhadap distribusi cahaya pada ruang pertemuan. Hasil simulasi DIALUX EVO menunjukkan perbedaan dengan melakukan perubahan reflektansi kaca. Sehingga, disarankan dalam menata atau membangun sebuah bangunan harus memperhatikan standar yang ada, terkhusus untuk ruang pertemuan agar pengguna ruang merasa nyaman. 


\section{Daftar Pustaka}

Koenigsberger, O.H. (1974). Manual of tropical housing and building: Climatic design. London: Longman.

Lam, William M.C. (1977). Perception and lighting as formgivers for architecture. US: McGraw-Hill Inc.

Lippsmeier, G. (1988). Bangunan tropis. Jakarta: Erlangga.

Manurung, P. (2012). Pencahayaan alami dalam arsitektur. Yogyakarta: Andi Offset. 